\title{
Private Health Care and Drug Quality in Germany - A Game-Theoretical Approach
}

\author{
Tristan Nguyen ${ }^{1}$ \& Karsten Rohlf \\ ${ }^{1}$ Department of Economics, WHL Graduate School of Business and Economics, Hohbergweg, Germany \\ Correspondence: Tristan Nguyen, Professor for Insurance and Health Economics, Department of Economics, \\ WHL Graduate School of Business and Economics, Hohbergweg 15-17, 77933 Lahr, Germany. Tel: \\ 49-78-2192-3865. E-mail: tristan.nguyen@whl-lahr.de
}

$\begin{array}{ll}\text { Received: August 21, } 2012 & \text { Accepted: September 14, } 2012 \quad \text { Online Published: September } 24,2012 \\ \text { doi:10.5539/ijef.v4n11p24 } & \text { URL: http://dx.doi.org/10.5539/ijef.v4n11p24 }\end{array}$

\begin{abstract}
Quality of medical treatment is a major goal of Germany's statutory health insurance system. According to our game theoretical approach, existing price-discrimination between statutory and private health insurance leads to a higher quality of innovative drugs. Hence, a move into the direction of a single payer health care (so-called citizens' insurance) should result in a reduction of innovative drugs' quality. Moreover, and in the case of citizens insurance's implementation, innovative drugs' price level should increase for patients with statutory health insurance. Furthermore, a similar effect is caused by the Act on the Reform of the Market for Medicinal Products (AMNOG) which leads to reduced prospects for price discriminations between the statutory and private health insurance system. In summary, the existence of private health insurance in Germany does not cause unfavourable cream-skimming. Rather the division of the German health care sector (statutory vs. private health insurance) results in higher drug quality at lower prices for patients with statutory health insurance.
\end{abstract}

Keywords: private health insurance, statutory health insurance, health reform, price discrimination, drug quality JEL-Classification: H40, I11, I13, I18, K20, K32

\section{Introduction}

Universality and access to good quality care are the overreaching values of European Health care systems (Council of the European Union, 2006). Additionally, the German legal framework states that statutory health insurance's (GKV) health care provision for the people has to be fulfilled to the generally accepted state of medical knowledge. Those insured by statutory health care insurance are entitled to receive medically necessary treatment of high quality. The goals of Germany's health care systems are access as well as quality. The GKV insures 70 million people in Germany, about $90 \%$ of German citizens, additionally 10\% of German citizens decided to use a private health insurance company (PKV). PKV's and GKV's legal frameworks are different: the GKV is dovetailed closely with the state and takes over governmental tasks. Instead of GKV, PKV is based on private autonomy and entrepreneurial freedom. The PKV's market is restricted to the area in which the GKV's administrative monopoly does not exist. Either PKV and GKV are differentiated, or they converge. On the one hand, the PKV is legally drawn near the GKV through the introduction of an obligation to contract, a prohibition of dismissal or the introduction of a base rate, on the other hand the GKV is legally drawn close to the PKV through possible deductibles, premium refunds or optional tariffs. This legislative act and the extension of membership in the statutory health insurance lead to a single-payer health care system, the so-called citizens insurance.

The existence of a full, private health insurance system in the future is questionable. It is not clear, whether the PKV's existence helps reaching the PKV's goal of good quality care, or if the GKV will be able to grant access to good quality care. A special purpose in this context is the access to innovative drugs, because increasing prices of innovative drugs will raise financial problems for statutory health insurance. High prices for innovative drugs are a result of the fact that pharmaceutical corporations get a monopoly for in-patent drugs. Contrarily, incentives to innovate justify an unrestricted monopoly on manufacturer prices. Monopoly prices allow producers to earn back research and development costs before prices decline through generic competition (Kifmann \& Neelsen, 2010). 
Drug prices in Germany are relatively high compared to other countries (Heuer, Mejer \& Neuhaus, 2007) and price differences for identical drugs between private and statutory health funds are a consequence of German legal drug price regulation (Arzneimittelpreisverordnung - AMPreisV). Drug expenses account for a fifth of statutory health funds' budgets and are their fastest growing expense (Kifmann \& Neelsen, 2010). High drug prices are also criticised by the PKV, for example the "absurd" price differences between PKV and GKV for identical drugs. Price differences had been borne by manufacturers' legal rebates to statutory health insurance funds and by a pricing treaty between the Federal Association of Statutory Health Insurance Fund and the Federal Union of German Associations of Pharmacists (Bundesvereinigung Deutscher Apothekerverbände ABDA). Negotiations between the Federal Union of German Associations of Pharmacists and the association of private health insurance funds did not result in a pricing treaty. In general, private health insurance funds seemed to have less power negotiating sufficient discount agreements. By the Act on the Reform of the Market for Medicinal Products (AMNOG), a new drug price regulation is set into law (Deutscher Bundestag, 2010). Manufacturers' legal rebates to GKV had been widened to PKV, additionally the PKV takes part in the introduced price negotiations between manufacturer and GKV. Therefore, drug prices between GKV and PKV should converge.

This paper focuses on the introduction of a single-payer health care in Germany. More precisely we analyze the impact of the PKV's existence on the GKV's drug price and the drug quality for innovative drugs. Additionally, our analysis enables us to give a brief prediction about the AMNOG's effect on drug quality and prices. Our analysis starts with a brief summary of the German drug pricing after the introduction of AMNOG. Afterwards, we introduce a game theoretic approach widely drawn from Acharyya and García-Alonso (2008, 2009). Based on our model, we show that a single-payer health care is derogatory especially to PKV's members. They are affected by increasing drug prices and decreasing drug quality. In spite of this, members of the PKV are also affected by decreasing drug quality but benefit from decreasing drug prices.

Our analysis also shows that the introduction of a new drug pricing legal framework leads to decreasing price discrimination between PKV and GKV, decreasing PKV drug prices and a decreasing drug quality. The German legal framework grants further latitude for the individual health insurance funds to formulate their own contracts with the pharmaceutical corporation, the prediction of these contracts will be important for innovative drugs' quality.

\section{Drug Pricing in Germany}

The Federal Institute for Drugs and Medical Devices (Bundesinstitut für Arzneimittel und Medizinprodukte BfArM) is the medical regulatory body in charge of the testing and authorisation of medicines in Germany. After authorisation and market-introduction, all members of the GKV are generally entitled to receive the new drug. Evaluation of the benefits and harms was introduced in Germany in 2004 as a consequence of health reform (GKV-Modernisierungsgesetz - GMG). Other countries had used the therapeutic value already to negotiate prices (Heuer et al., 2007). A novelty had been the standards that the Institute for Quality and Efficiency in Health Care (Institut für Qualität und Wirtschaftlichkeit im Gesundheitswesen - IQWiG) and the Federal Joint Committee (Gemeinsamer Bundesausschuss - G-BA) had set.

With the introduction of AMNOG in 2011, the evaluation of benefits and harms takes place after market introduction of new drugs with a new active ingredient. Depending on the existence of an added benefit, price negotiations between the Federal Association of Statutory Health Insurance Funds (GKV-Spitzenverband), PKV and the manufacturer begin after six months. Health insurance and manufacturers have six months to agree on a new drug price in the form of a discount on the original price. If price negotiations fail, an arbitral process is introduced and an award is made up to three months after the failure of price negotiations. Independent health insurance funds are able to negotiate additional individual discounts with the manufacturer on their own after pricing.

The drug becomes part of a reference price cluster, if no added benefit is proven. In the latter case the new drug is not an innovative drug we are focussing on. The G-BA published several definitions of added benefits in 2011:

$>$ A lasting significant improvement of the therapy-relevant benefit that is not reached with the appropriate comparable therapy is called a "major" added benefit.

$>$ A clear improvement of the therapy-relevant benefit that is not reached with the appropriate comparable therapy is called a "considerable" added benefit.

$>$ A moderate improvement of the therapy-relevant benefit that is not reached with the appropriate comparable therapy is called a "minor" added benefit. 
If data does not allow quantifying the added benefit, it is called a non-quantifiable added benefit.

In other cases there is no added benefit. § 35a (1) SGB V states that if the pharmaceutical corporation does not submit fully objective evidence, an added benefit is not mentioned. The added benefit of orphan drugs are always proven with authorisation [§35a (1) SGB V]. In addition to the definitions of the added benefit, the IQWiG defines several cases of evidence:

$>$ If there are two or more studies with mostly high certainty of results and consistent results, IQWiG labels it a "Proof".

$>$ If there are two or more studies with consistent results but mostly moderate certainty of results, IQiG labels it an "Indication". An indication is also stated if there is only one study with high certainty of results and statistically significant effects.

$>$ If there are two or more studies with mostly low certainty of results and consistent results, IQWiG states a "Hint". A hint is also stated if there is only one study with moderate certainty of results and statistically significant effects.

\begin{tabular}{|c|c|c|c|c|c|}
\hline & Proof & Indication & Hint & Orphan & $\begin{array}{l}\text { Objective Evidence Not } \\
\text { Fully Submitted }\end{array}$ \\
\hline \multicolumn{6}{|l|}{ Major added benefit } \\
\hline $\begin{array}{l}\text { Considarable added } \\
\text { benefit }\end{array}$ & Ticagrelor & Abirateronacetat & & & \\
\hline \multirow{2}{*}{ Minor added benefit } & & \multirow{2}{*}{ Cabazitaxel } & Eribulin & & \\
\hline & & & Fingolimod & & \\
\hline \multirow{2}{*}{$\begin{array}{l}\text { Non-quantifiable } \\
\text { added benefit }\end{array}$} & & Boceprevir & & \multirow{2}{*}{ Pirfenidon } & \\
\hline & & Telaprevir & & & \\
\hline \multirow{8}{*}{ No added benefit } & & & & & Aliskiren/Amlodipin \\
\hline & & & & & $\begin{array}{l}\text { Azilsartan Medoxomil } \\
\text { (calcium salt) }\end{array}$ \\
\hline & & & & & Bromfenac \\
\hline & & & & & Linagliptin \\
\hline & & & & & $\begin{array}{l}\text { microbial Collagenase from } \\
\text { Clostridium histolyticum }\end{array}$ \\
\hline & & & & & Pitavastatin \\
\hline & & & & & Regadenoson \\
\hline & & & & & Retigabin \\
\hline
\end{tabular}

Figure 1. Results of the Active Ingredients' Evaluation of Benefits and Harms since 2011

Figure 1 represents results of the active ingredients' evaluation of benefits and harms since 2011 Our definition of innovative drugs is based on Acemoglu and Lynn (2004) they defined radical innovations as drugs with new introduced active ingredient. Because drugs with new active ingredient but no added benefit become part of a price cluster we exclude these drugs, further orphan drugs are not innovative drugs in our definition. Related to German legal framework we focus only on drugs with new marketed active ingredients that have a proof, indication or hint of their added benefits.

\section{The Model}

Our model is based on Acharayya and García-Alonso (2009). They showed that asymmetric health care systems can arise even if countries are ex-ante symmetric when international price discrimination is possible. It is also shown that regardless of any intra-country income differences, parallel imports result in a lower level of health-care innovation. Earlier findings about product quality and monopoly are related to Mussa and Rosen (1978), who found out that product quality is generally lower in a monopoly than in competitive situation. Later Kim and Kim (1996) introduced spill-over effects in costs and demonstrate that higher marginal willingness to pay does not necessarily imply higher quality being offered. A different approach is chosen by Bardey, Brommier and Jullien (2010). They found that reference pricing negatively affects the intensity of research, especially small innovations using time as an independent variable.

Our model focuses on two countries deciding independently about aspects of their health care systems, 
especially subsidizing access to universal health care. In Germany solidarity-based funding within the GKV is indeed subsidizing the poorer members. Access to new medicines is legally granted automatically after approval [§ 31 SGB V]. These subsidies are taken into account by suppliers, especially profit maximizing pharmaceutical corporations as drug manufacturers deciding about price and quality of new drugs within their systematic R\&D process (DiMasi, Hansen, Grabowski \& Lasagna, 1991; DiMasi, Hansen, \& Grabowski, 2003). These subsidies increase pharmaceutical firms' marginal revenues and should result in positive effects on pharmaceutical innovation (Sloan \& Hsieh, 2008). After market introduction, patients decide about buying the medicine. Their decision depends only on utility aspects.

Countries are independent in their subsidy decision; manufacturers take the countries' decisions into account when deciding about quality and price of the new drugs. Patients' decisions also depend on price and quality of the new drug as well as the subsidy decision of their country. Figure 1: Sequential structure of the decision game in a two-country model illustrates the model structure like an extensive form in game theory. Players are country $1(C 1)$ and $2(C 2)$, a multinational pharmaceutical corporation $(M N C)$ and Patients $(P a)$. Their payoffs are wealth $\left(W_{l}, W_{2}\right)$, profit $(\pi)$ and utility $(U)$.

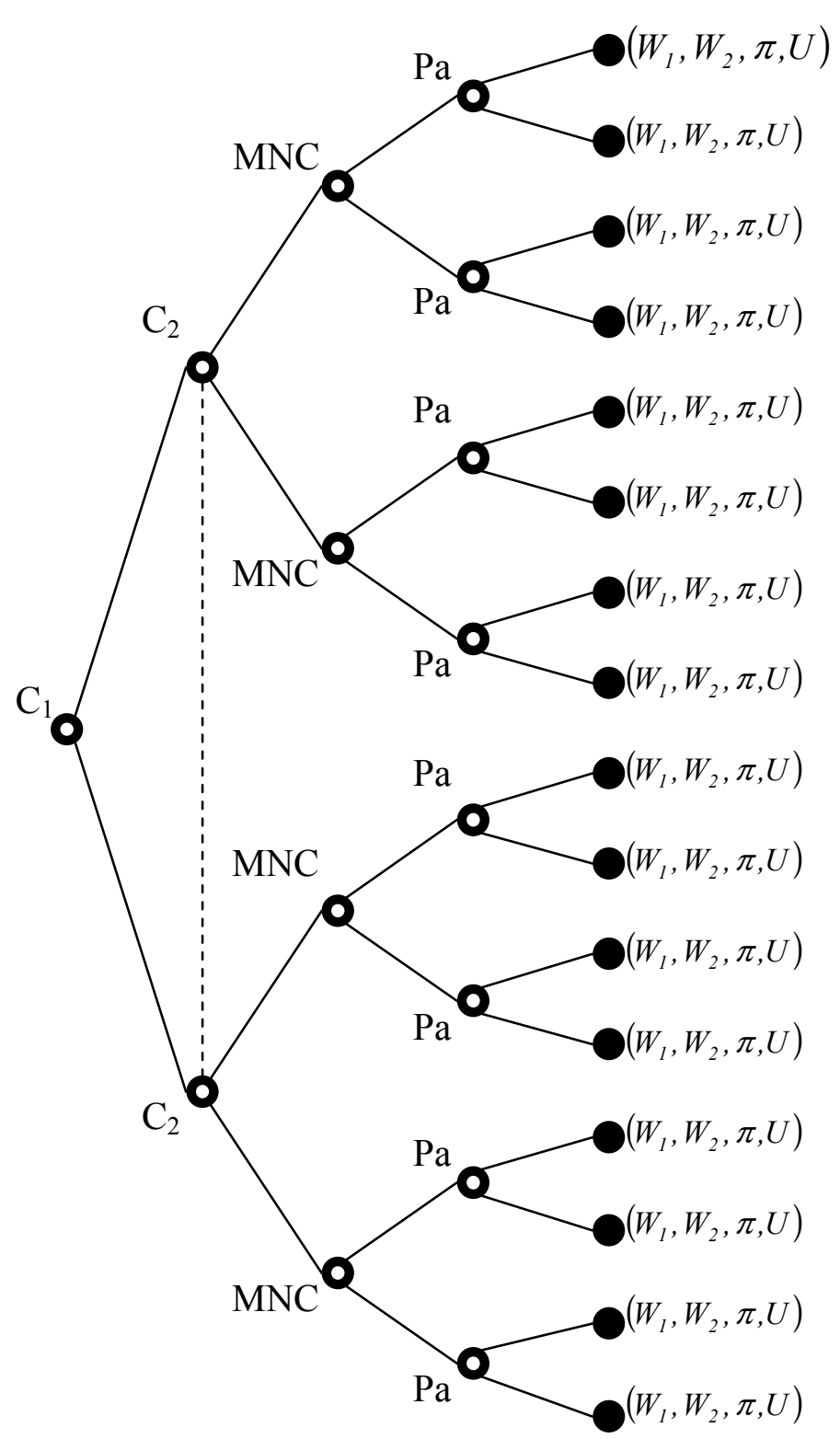

Figure 2. Sequential structure of the decision game in a two-country-model 
We consider two types of citizens in the countries; one type earns ordinary wages $(U)$ and the other type is high wage earners $(O)$. Incomes are $y_{U}$ and $y_{O}$ with $y_{U}<y_{O}$. Let the number of citizens or consumers with a high wage in country 1 be $n_{1 O}$ and $n_{1 U}$ with an ordinary wage. Respectively, country 2 consists of citizens $n_{2 O}$ and $n_{2 U}$. Different incomes and the population of the countries can be modelled by varying the number of income brackets. Securing for a higher absolute and relative number of high wage earners implies $n_{1 O}>n_{2 O}$ and $n_{1 O} / n_{I U}>n_{2 O} / n_{2 U}$.

Reducing health inequalities of different population groups is the goal of different policies. These inequalities are mainly driven by general living conditions, social behaviour and income as a requirement for access to health care (European Parliament, 2011). Health inequalities are not only a consequence of economic and ecological factors but mainly a consequence of access factors. Following this argumentation, it is not illness probability that differs across income groups but possibly their access to health care. To simplify, each citizen should be affected by a widespread disease and could be treated with a drug for one year.

The new drug's quality is denoted as $s$. The law of diminishing marginal returns holds true for drug quality, for increasing $\mathrm{R} \& \mathrm{D}$ expenses $(C)$ quality increases at decreasing rates:

$$
\frac{\partial s}{\partial C}>0, \frac{\partial^{2} s}{\partial C^{2}} \leq 0
$$

A simple function for drug quality related to $R \& D$ effort would be:

$$
s(C)=\sqrt{2 \cdot C} \text {. }
$$

Following the related literature (Acharyya et al., 2008, 2009; Bardey et al., 2010; Brekke et al., 2007), we assume no other costs except the (sunk) R\&D expenses which lead to the cost function:

$$
C=\frac{1}{2} s^{2}
$$

To calculate the MNCs profits, information about revenues are necessary. Revenues depend on sales volume and price. Sales volume itself depends on the coverage decisions in both countries, i.e. only high wage earners buy the drug (partial coverage) or high and ordinary wage earners buy the drug (universal coverage).

In general, consumers decide to buy a product if their individual utility is equal or exceeds the price - or in our case the subsidized price. Each consumer has an identical valuation for a particular product quality (Mussa \& Rosen, 1978; Kim \& Kim, 1996; Acharyya, 1998, 2005). The consumer's valuation should be linearly related to the income level and a representative consumer $k, k=O, U$, derives utility from buying a drug:

$$
U_{k}=u\left(y_{k}, s\right) \text {. }
$$

Related to Gossen's law, utility increases at a decreasing rate with the higher quality of the drug:

$$
\frac{\partial U}{\partial s}>0, \frac{\partial^{2} U}{\partial s^{2}} \leq 0 .
$$

Since $y_{O}>y_{U}$, so,

$$
u\left(y_{O}, s\right)>u\left(y_{U}, s\right) \forall s
$$

Thus, a high wage earner derives greater utility than an ordinary wage earner from the same quality drug. Following Grossman's model, additional time available for work or leisure, i.e. time not been taken over by illness, increases the individuals' utility directly and indirectly through market and non-market activity (Grossman, 1972). A high wage earner has a greater addition to his utility and hence, would be willing to pay more at the margin for a better quality that is created:

$$
\frac{\partial u\left(y_{O}, s\right)}{\partial s}>\frac{\partial u\left(y_{U}, s\right)}{\partial s} \forall s .
$$


We assume a linear utility function that satisfies all three conditions, letting the reservation utility be zero the individuals buy the drug, if its (subsidized) price is below the utility:

$$
U_{k}=y_{k} \cdot s \geq P_{i}-\gamma_{i k} .
$$

A subsidy to the high income earners would not make any sense, so $\gamma_{i}$ denotes the subsidy to the ordinary wage earners. Price discrimination between countries are possible but not within countries.

The MNC is free to choose its location and the MNC's profits are not taken into account for calculating welfare. According to the literature our wealth function is:

$$
W_{i}=n_{i O}\left(y_{O} \cdot s-P_{i}\right)+n_{i U}\left(y_{U} \cdot s-P_{i}\right) .
$$

Obviously a subsidy only makes sense if income differs sufficiently. If not, universal coverage is preferred by MNC even without a subsidy. This income difference in terms of the high wage earner's income is denoted as $y_{O}^{\overline{\min }}$ and will be investigated later. If subsidies are too high, a welfare loss occurs and we assume an additional income boarder. This income boarder is denoted as $y_{O}^{\overline{\max }}$ and will also be investigated later. For subsidies within the model the following condition is necessary:

$$
y_{O}^{\overline{\min }} \geq y_{O} \geq y_{O}^{\overline{\max }} .
$$

\section{Drug Quality and Subsidies}

\subsection{Game Reduction and Drug Quality}

The consumer's decision is stated in (2). Consumers will buy the drug if the following conditions holds true

$$
P_{i} \leq y_{U} \cdot s+\gamma_{i},
$$

respectively

$$
P_{i} \leq y_{O} \cdot s
$$

Otherwise consumers will not buy the medicine. Regarding utility maximization, other consumption decisions do not make sense and the consumer's decisions can be predicted directly.

The MNC will not offer a price below the price stated in the conditions above, because it would negatively affect revenues and profits. Prices will be:

$$
P_{i}=y_{U} \cdot s+\gamma_{i}
$$

or as the case may be,

$$
P_{i}=y_{U} \cdot s+\gamma_{i} \text {. }
$$

For being determined in price setting, the MNC's only possibility for profit maximization is varying the drug quality. The MNC's drug quality decision refers to the surrounding conditions. That is to say, drug quality is influenced by the countries' covering decisions. Regarding the framework there are three possible alternatives:

$1^{\text {st }}$ Both countries provide full coverage, i.e. subsidizing the drug consumption.

$2^{\text {nd }}$ Only one country provides full coverage, i.e. only in country 1 or 2 the drug consumption is subsidized.

$3^{\text {rd }}$ both countries provide partial coverage, i.e. no country subsidizes the drug consumption.

These alternatives will be further analyzed. The MNC maximizes its profits in choosing the drug quality depending on the countries' subsidy $\gamma_{i}$. If both countries provide full coverage, subsidizing the drug consumption in the high of $\gamma_{i}^{C}$, the resulting price is $P_{i}=y_{U} \cdot s+\gamma_{i}^{C}$ in both countries. Calculating the MNC's revenue leads to:

$$
R_{F C}^{D}(s)=\sum_{i=1}^{2}\left(n_{i O}+n_{i U}\right)\left(y_{U} s+\gamma_{i}^{C}\right)^{2} .
$$

Drug price, numbers of high and ordinary wage earners in the countries and subsidies are given and the MNC's only possibility to maximize profits is to vary drug quality. Revenues increase with increasing drug quality and vice versa. (1) states that the MNC's costs depend only on drug quality and also the MNC's profits $\pi_{F C}^{D}$ 
depend only on drug quality:

$$
\pi_{F C}^{D}(s)=\sum_{i=1}^{2}\left(n_{i O}+n_{i U}\right)\left(y_{U} s+\gamma_{i}^{C}\right)-\frac{1}{2} s^{2} .
$$

Maximizing the MNC's profits for universal coverage in both countries leads to the drug quality:

$$
s_{F C}^{D}=y_{U} \sum_{i=1}^{2}\left(n_{i O}+n_{i U}\right) .
$$

Universal coverage in only one country subsidizing their consumers' drug consumption with the subsidy $\gamma_{\mathrm{i}}^{\mathrm{D}}$ and no subsidy in the other country results in the prices $P_{i}=y_{U} \cdot s+\gamma_{i}^{D}$ and $P_{j}=y_{O} \cdot s$ respectively. The MNC's profit is:

$$
\pi_{F C i}^{D}=\left(n_{i O}+n_{i U}\right)\left(y_{U} s+\gamma_{i}^{D}\right)+n_{j O} s-\frac{1}{2} s^{2} \quad(i \neq j) .
$$

Resulting in a quality level equal to:

$$
s_{F C i}^{D}=y_{U}\left(n_{i O}+n_{i U}\right)+n_{j O} y_{O} .
$$

Partial coverage in both countries results in price $P_{i}=y_{O} \cdot s$ in both countries and profits:

$$
\pi_{P C}^{D}(s)=y_{O} s \sum_{i=1}^{2} n_{i O}-\frac{1}{2} s^{2} .
$$

Thus,

$$
s_{P C}^{D}=y_{O} \sum_{i=1}^{2} n_{i O} .
$$

Notably, all drug qualities are independent of the height of the subsidies. Given the surrounding conditions there is only one possible combination of drug quality and price being offered by the MNC and the MNC's decision can be predicted without any game theoretic approach. Wealth, drug quality and coverage level depends only on the countries' subsidy decision (see figure 3 ).

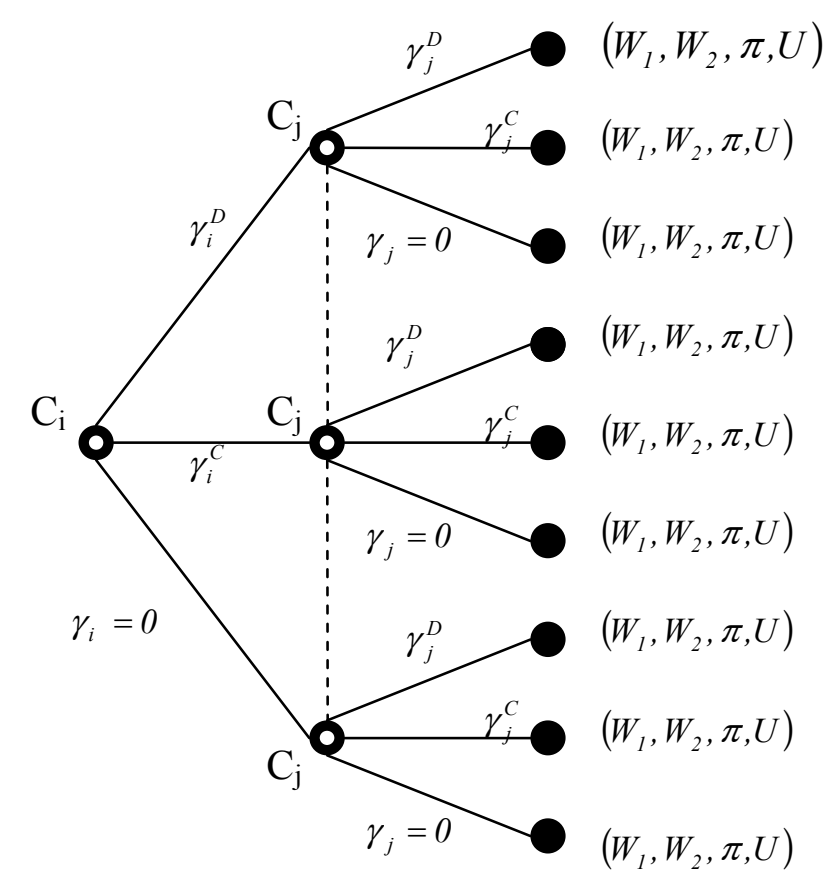

Figure 3. Reduced Game Matrix 


\subsection{Optimal Subsidy Level}

The MNC's optimal drug quality choice under the assumption of profit maximization has been analyzed above. To provide full coverage, the MNC's profits have to be higher with a consumer's subsidy than without a subsidy. To provide full coverage in country $i$ - and partial coverage in country $\mathrm{j}$ - the following condition has to be fulfilled:

$$
\pi_{F C_{i}}^{D}(s) \geq \pi_{P C}^{D}(s)
$$

The quality level is induced by the subsidy decision. Country $i$ provides universal coverage subsidizing drug consumption at an appropriate level. And the MNC prefers full coverage in country $i$ and partial coverage in country $j$, i.e. $(6)>(8)$. Thus,

$$
\gamma_{i}^{D} \geq \frac{\frac{1}{2}\left[\sum_{i=1}^{2} n_{i O} \cdot y_{O}\right]^{2}-\frac{1}{2}\left[y_{U}\left(n_{i O}+n_{i U}\right)+n_{j O} y_{O}\right]^{2}}{n_{i O}+n_{i U}} .
$$

Full coverage in both countries is preferred by the MNC, if $(5)>(8)$. Thus,

$$
\gamma_{i}^{C}=\frac{\frac{1}{2}\left[y_{O} \sum_{i=1}^{2} n_{i O}\right]^{2}-\frac{1}{2}\left[y_{U} \sum_{i=1}^{2}\left(n_{i O}+n_{i U}\right)\right]^{2}-\gamma_{j}^{C}\left(n_{j O}+n_{j U}\right)}{n_{i O}+n_{i U}}(i \neq j) .
$$

In spite of $\gamma_{i}^{D} \gamma_{i}^{C}$ is dependent of the other country's subsidy decision. Nevertheless, it is necessary that the MNC prefers full coverage in both countries to full coverage in only one country: (5) > (6). Thus,

$$
\gamma_{i}^{\min }=\frac{\frac{1}{2}\left[y_{O} \sum_{i=1}^{2} n_{i O}\right]^{2}-\frac{1}{2}\left[y_{U} \sum_{i=1}^{2}\left(n_{i O}+n_{i U}\right)\right]^{2}-\gamma_{j}^{\min }\left(n_{j O}+n_{j U}\right)}{n_{i O}+n_{i U}}(i \neq j) .
$$

$\gamma_{i}^{\min }=\gamma_{i}^{C}$ resulting from $\gamma_{j}^{\min }=\gamma_{j}^{C}$ and (10) is identical to (11). If both countries decide to provide full coverage, a simple solution could be offering the same subsidy level $\gamma_{1}^{\min }=\gamma_{2}^{\min }$ and (11) yields:

$$
\gamma_{1}^{i d e n t}=\gamma_{2}^{i d e n t}=\frac{\left[y_{O}\left(n_{1 O}+n_{2 O}\right)\right]^{2}}{2\left(n_{1 O}+n_{1 U}+n_{2 O}+n_{2 U}\right)}-\frac{1}{2} \cdot y_{U}^{2}\left(n_{1 O}+n_{1 U}+n_{2 O}+n_{2 U}\right)
$$

\section{Income Differences and Subsidy Level}

\subsection{Minimum Income Difference}

Equation (4) implies that a subsidy is only necessary, if income differs sufficiently. This condition implies a positive subsidy. Thus, (9) $>0$ in the case $o$

f unilateral full coverage:

$$
y_{O} \geq \frac{n_{i O}+n_{i U}}{n_{i O}} \cdot y_{U}
$$


And the income difference from (4) can be specified as:

$$
y_{O} \geq \frac{n_{i O}+n_{i U}}{n_{i O}} \cdot y_{U}=y_{O}^{\min } .
$$

The condition of a positive subsidy has to hold true also in the case of bilateral universal coverage and income distribution results from $(12)>0$ :

$$
y_{O}>\frac{n_{1 O}+n_{1 U}+n_{2 O}+n_{2 U}}{n_{1 O}+n_{2 O}} \cdot y_{U}=y_{O}^{\min } .
$$

Given the assumptions about income and population structure in both countries the condition is always fulfilled, if (13) holds true. From equation (13) it can be verified that drug quality decreases with increasing coverage:

$$
s_{P C} \geq s_{F C i} \geq s_{F C}
$$

Obviously the monopolistic MNC reduces quality not quantity, if subsidies are granted. With a decrease in the new drug's quality there is a shift from breakthrough to incremental innovations. DiMasi and Paquette (2004) estimates that marketing exclusivity of the breakthrough drug has fallen dramatically. This states also a shift to incremental innovations over time. It might be interesting to additionally investigate the link between coverage and marketing exclusivity over time. Notably, a stream of incremental innovations can often exceed the effect of breakthroughs. By (13) we obtain for (9)

$$
\gamma_{i}^{D} \geq \frac{\frac{1}{2}\left[\sum_{i=1}^{2} n_{i O} \cdot y_{O}\right]^{2}-\frac{1}{2}\left[y_{U} \cdot \sum_{i=1}^{2}\left(n_{i O}+n_{i U}\right)\right]^{2}}{n_{i O}+n_{i U}} .
$$

Taking (11) into account it is straightforward that:

$$
\gamma_{i}^{\min } \geq \gamma_{i}^{D}-\frac{n_{j O}+n_{j U}}{n_{i O}+n_{i U}} \cdot \gamma_{j}^{\min }
$$

The subsidy levels $\gamma_{i}^{D}$ and $\gamma_{i}^{\min }$ differ about the weighted foreign subsidy level and for every non-negative foreign subsidy:

$$
\gamma_{i}^{D} \geq \gamma_{i}^{\min }
$$

holds true. (11a) states also that a marginal subsidy has to be granted in order to provide bilateral full coverage, because of $\gamma_{j}^{\min }=0 \Rightarrow \gamma_{i}^{\min }=\gamma_{i}^{D}$ and vice versa. Any country's marginal subsidy has to be greater than zero but depends on the other country's subsidy. Transforming (11a) reveals that:

$$
\left(n_{i O}+n_{i U}\right) \cdot \gamma_{i}^{\min }+\left(n_{j O}+n_{j U}\right) \cdot \gamma_{j}^{\min } \geq\left(n_{i O}+n_{i U}\right) \cdot \gamma_{i}^{D}
$$

The level of subsidy does not only depend on the other country's subsidy but also on the countries' population. The marginal subsidy (bilateral universal full coverage) increases with increasing population but will not exceed 
the level for unilateral full coverage. By (9) we obtain for (11):

$$
\gamma_{i}^{\min }=\frac{\frac{1}{2}\left[y_{U}\left(n_{j O}+n_{j U}\right)+n_{i O} y_{O}\right]^{2}-\frac{1}{2}\left[y_{U}\left(n_{i O}+n_{i U}+n_{j O}+n_{j U}\right)\right]^{2}}{n_{i O}+n_{i U}} .
$$

Because of (13) $\gamma_{i}^{\min }$ is positive and the absolute minimum subsidy for universal coverage in country $i$. The absolute minimum subsidy increases with increasing income difference. This holds true for (9) also. For (11) and (9) we obtain also:

$$
\gamma_{i}^{D}=\frac{1}{2} \cdot y_{U} \cdot\left(n_{i O}+n_{i U}\right) \cdot \frac{n_{j O}}{n_{i O}}
$$

The necessary subsidy to persuade unilateral full coverage increases with increasing population and decreasing relative number of high wage earners. That is to say providing full coverage is more difficult for larger countries with lower per capita income than for smaller ones with higher income.

\subsection{Maximum Income Difference}

In addition to the minimum level of income inequality, the maximum level of income inequality stated in (4) has to be taken into account. To make sense, a subsidy has to fulfil two conditions: first it must ensure full coverage; second a subsidy has to increase wealth. The first condition is fulfilled by (13). The second condition will be investigated now. In the case of partial coverage, only the high wage earners will be provided with the new drug and by (3) and (2) we obtain:

$$
W_{i}=n_{i O} \cdot\left(y_{O} \cdot s-P_{i}\right)=n_{i O} \cdot\left(y_{O} \cdot s-y_{O} \cdot s\right)=0 .
$$

The wealth improvement condition is:

$$
W_{i}=n_{i O} \cdot s \cdot\left(y_{O}-y_{U}\right)-\gamma_{i} \cdot\left(n_{i O}+n_{i U}\right) \geq 0
$$

Thus, the maximum subsidy is:

$$
\gamma_{i}^{\max } \equiv s \frac{n_{i O}}{n_{i O}+n_{i U}}\left(y_{O}-y_{U}\right) \geq \gamma_{i} .
$$

The maximum subsidy increases with increasing drug quality and increasing income range $\left(y_{O}-y_{U}\right)$. It decreases with an increasing number of normal wage earners. It is easier for relatively rich countries to subsidize their lower number of normal wage earners than the other way round.

For subsidizing unilateral full coverage $(14) \geq(9)$ has to hold true, to be more precise:

$$
\gamma_{i}^{\max }=\frac{n_{i O} \cdot s_{F C i} \cdot\left(y_{O}-y_{U}\right)}{n_{i O}+n_{i U}} \geq \gamma_{i}^{D} .
$$

And the maximum level of income inequality is straightforward: 


$$
y_{O}^{\overline{\max }}=\frac{n_{i O}^{2}+n_{i O} n_{i U}+n_{i U} n_{j O}+\sqrt{\left(n_{i O}^{2}+n_{i O} n_{i U}+n_{i U} n_{j O}\right)^{2}+n_{i O}^{2} n_{i U}^{2}-n_{i O}^{4}}}{n_{i O}^{2}} y_{U},
$$

respectively

$$
y_{O}^{\overline{\max }}=\left[1+\frac{n_{i U}}{n_{i O}}+\frac{n_{i U} n_{j O}}{n_{i O}^{2}}+\sqrt{\frac{2 n_{i U}}{n_{i O}}+\frac{2 n_{i U} n_{j O}}{n_{i O}^{2}}+\frac{2 n_{i U}^{2}+2 n_{i U}^{2} n_{j O}}{n_{i O}^{3}}+\frac{n_{i U}^{2} n_{j O}^{2}}{n_{i O}^{4}}}\right] \cdot y_{U} .
$$

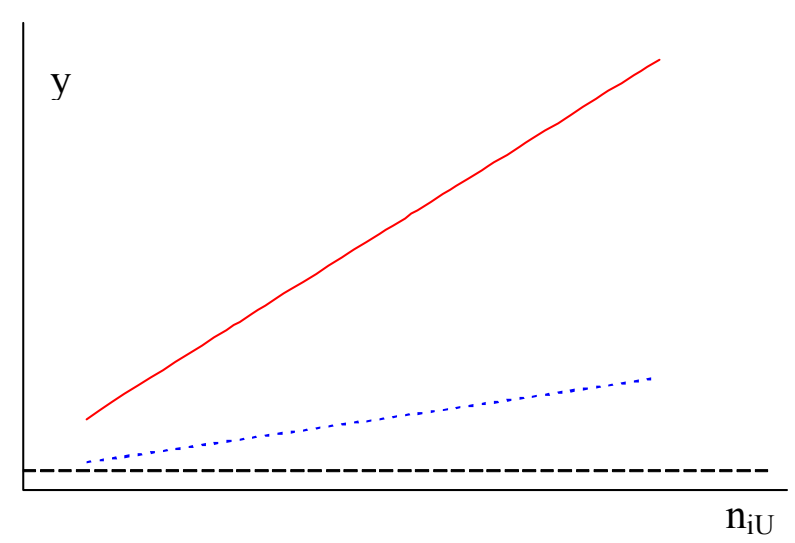

....... Minimum Income

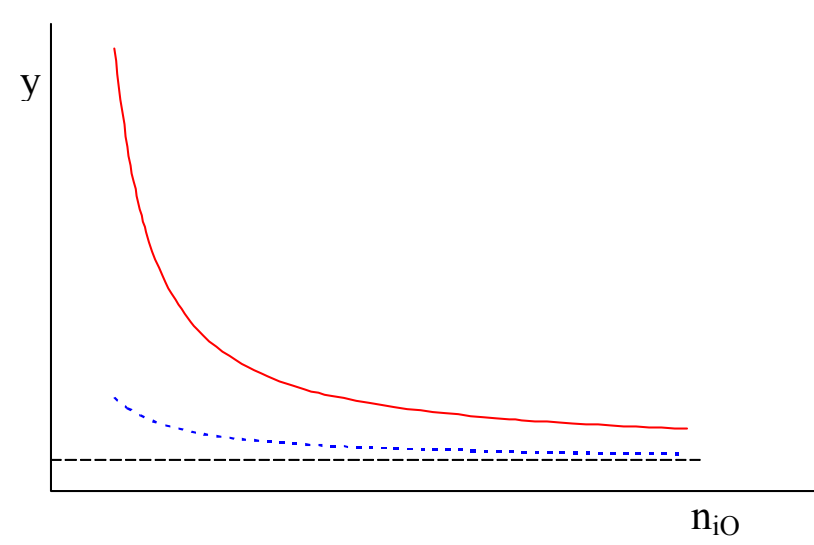

$--\mathrm{y}_{\mathrm{U}}$

Figure 4. Income Range

The maximum level of income inequality decreases with an increasing number of high wage earners asymptotical to the ordinary wage and increases with an increasing number of ordinary wage earners and foreign high wage earners respectively. It has already been shown that (9) > (11) and (14) $\geq(11)$ is fulfilled, if (15) holds true.

Figure 4 summarizes the income analysis. Therefore maximum and minimum income disparities - (13) and (15) - are plotted depending on $n_{i U}$ and $n_{i O}$ respectively. As an orientation, the ordinary income is plotted. For an increasing number of ordinary wage earners the income range increases, also the minimum income disparity increases. That is to say income disparity has to be larger in relatively poorer countries in order to make sense of a subsidy. In spite of this result, the income range decreases asymptotical to the ordinary wage with an increasing number of high wage earners. That is to say, in relatively rich countries welfare decreases are implied by a subsidy shortage.

\subsection{Subsidy Setting}

A subsidy is necessary if the income range (4) holds true. The possible subsidies are between $\gamma_{i}^{D} \geq \gamma_{i} \geq 0$. No subsidy induces bilateral partial coverage and welfare levels of $W_{i, j_{P C}}^{D}=0$. In the case of unilateral full coverage with subsidy $\gamma_{i}^{D}$ country $i$ 's welfare is:

$$
W_{i_{F C i}}^{D}=\frac{1}{2} y_{O}^{2}\left(-n_{i O}^{2}\right)+y_{O} y_{U}\left(n_{i O}^{2}+n_{i O} n_{i U}+n_{i U} n_{j O}\right)+\frac{1}{2} y_{U}^{2}\left(n_{i U}^{2}-n_{i O}^{2}\right)
$$

Because of (14)>(9), $W_{i_{F C}}^{D} \geq 0$ holds true. The other countries' welfare is zero. If the non-subsidizing country decides to provide full coverage subsidizing the marginal subsidy, (Note 1) drug quality decreases and country $i$ 's welfare decreases to:

$$
W_{i_{F C}}^{D, \gamma_{i}^{D}}=-\frac{1}{2} y_{O}\left(n_{i O}^{2}+2 n_{i O} n_{j O}\right)+y_{O} y_{U}\left(n_{i O}^{2}+n_{i O} n_{i U}+2 n_{i O} n_{j O}+n_{i O} n_{j U}+n_{i U} n_{j O}\right)
$$




$$
-\frac{1}{2} y_{U}^{2}\left(n_{i O}^{2}+2 n_{i O} n_{j O}+2 n_{i O} n_{j U}-n_{i U}^{2}\right)
$$

And welfare in country $j$ increases. By (13) the welfare is equal to:

$$
W_{j_{F C}}^{D, \gamma_{i}^{D}} \geq n_{j U} y_{U}^{2}\left(n_{i O}+n_{i U}+n_{j O}+n_{j U}\right)-\left(n_{j O}+n_{j U}\right) \gamma_{j}^{\min } .
$$

For $\gamma_{j}^{\min }$ being slightly greater than zero welfare is approximately:

$$
W_{j_{F C}}^{D, \gamma_{i}^{D}} \geq n_{j U} y_{U}^{2}\left(n_{i O}+n_{i U}+n_{j O}+n_{j U}\right) .
$$

And the welfare gain depends on population structure. The welfare in country $i$ remains unchanged, if country $j$ decides for a higher subsidy than the marginal one. A higher $\gamma_{j}$ would only affect country $j$. The subsidy $\gamma_{j}^{\text {ident }}$ would result in the welfare:

\begin{tabular}{|c|c|c|c|c|c|c|c|}
\hline & \multicolumn{6}{|l|}{ Country $j$} \\
\hline & & 0 & $\gamma_{j}^{\min }$ & $\ldots$ & $\gamma_{j}^{\text {ident }}$ & $\ldots$ & $\gamma_{j}^{\mathrm{D}}$ \\
\hline \multirow{6}{*}{ Country $i$} & 0 & $0 / 0$ & $0 / 0$ & $\ldots$ & $0 / 0$ & $\ldots$ & $0 / W_{j_{F C}}^{D}$ \\
\hline & $\gamma_{i}^{\min }$ & $0 / 0$ & $0 / 0$ & $\ldots$ & $0 / 0$ & $\ldots$ & $\begin{array}{l}W_{i_{F C}^{D}}^{D, \gamma_{j}^{D}} \\
W_{j_{F C}}^{D, \gamma_{j}^{D}}\end{array}$ \\
\hline & $\vdots$ & $\vdots$ & $\vdots$ & & $\vdots$ & & $\vdots$ \\
\hline & $\gamma_{i}^{\text {ident }}$ & $0 / 0$ & $0 / 0$ & $\cdots$ & $\begin{array}{l}W_{i_{F C}}^{D, \gamma_{i}^{\text {dent }}} \\
W_{j_{F C}}^{D, \gamma_{j}^{\text {deent }}}\end{array}$ & $\ldots$ & $\begin{array}{l}W_{i_{F C}^{D,} \gamma_{i}^{\text {ient }}} \\
W_{j_{F C}}^{D, \gamma_{j}^{D}}\end{array}$ \\
\hline & $\vdots$ & $\vdots$ & $\vdots$ & & $\vdots$ & & $\vdots$ \\
\hline & $\gamma_{i}^{\mathrm{D}}$ & $W_{i_{F C}^{D}}^{D, \gamma_{i}^{D}} / 0$ & $\begin{array}{l}W_{i_{F C}}^{D, \gamma_{i}^{D}} \\
W_{j_{F C}}^{D, \gamma_{i}^{D}}\end{array}$ & $\cdots$ & $\begin{array}{l}W_{i_{F C}^{D}}^{D, \gamma_{i}^{D}} \\
W_{j_{F C}}^{D, \gamma_{j}^{\text {ident }}}\end{array}$ & $\cdots$ & $\begin{array}{l}W_{i_{F C}}^{D, \gamma_{i}^{D}} \\
W_{j_{F C}}^{D, \gamma_{j}^{D}}\end{array}$ \\
\hline
\end{tabular}

$$
W_{j_{F C}}^{D, \gamma_{j}^{i d e n t}}=y_{U}^{2} \frac{n_{j O}^{2} 3 n_{j U}+n_{j O} n_{i O}+n_{i U}+n_{j O}+n_{j U}^{2}-n_{j O}+n_{j U}^{3} n_{i O}+n_{j O}^{2}}{2 n_{j O}^{2} n_{i O}+n_{i U}+n_{j O}+n_{j U}} .
$$

Welfare is zero, if the subsidies are not high enough. Summing up these findings results in the game matrix:

Figure 5. Game Matrix for Two Countries

Country $i$ 's best response for $\gamma_{j}=0$ is subsidy $\gamma_{i}^{D}$. This is also the best response for country $j$ 's marginal subsidy. Country $i$ 's best response for the identical subsidy in country $j$ is $\gamma_{i}^{i d e n t}$. In the case of the unilateral full coverage subsidy in country $j$, country $i$ 's best response is the marginal subsidy. Country $j$ 's best response 
are analogues.

Although a final analysis is not possible without information about income and population structure, it can be stated that the first-mover has an advantage over the other country. Because the first-mover is able to determine the second mover's strategy choice, he is able to increase his own welfare choosing the marginal subsidy. Figure 6 illustrates the countries' best response function:

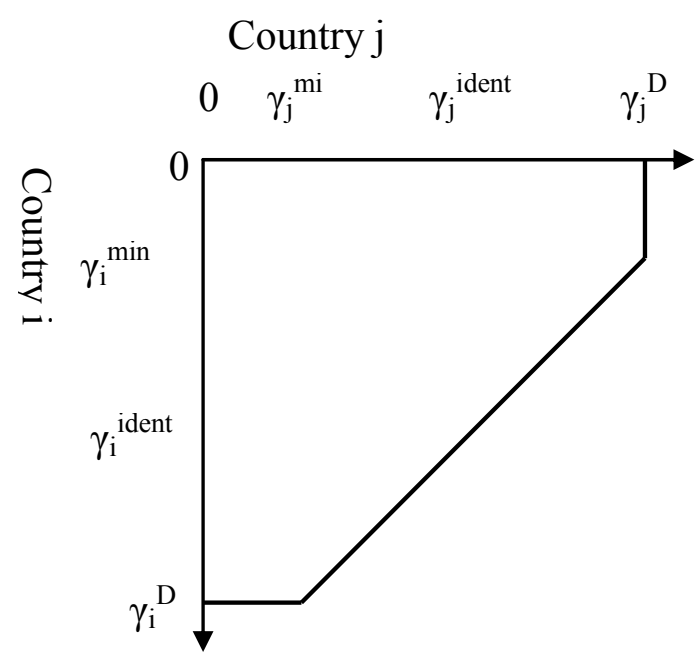

Figure 6. Best Response Functions

\section{Importance of Private Health Insurance in Germany}

Our model enables us to analyze the PKV's importance for drug price and quality. Therefore we model the two theoretic countries "PKV-country" and "GKV-country". In general because of the German legal framework, it is assumed that especially high income young citizens are members of the PKV in Germany. And the PKV-country is the richer country. According to the annual income threshold, letting the number of ordinary wage earners in a PKV-country be zero is an appropriate simplification: $n_{P U}=0$.

Without any ordinary income earners a subsidy within a PKV-country is not necessary and universal coverage is given automatically. Basing the insurance premium on the principle of equivalence is a logical consequence. A GKV-country consists of high and average income earners: $n_{G O} \geq 0$ und $n_{G U} \geq 0$. To provide universal coverage within a GKV-country (FCG) results in subsidy $\gamma_{G}^{D}$ according to (9). This equals the solidarity-based funding of the GKV. Taking the subsidy strategies into account, the drug quality is analogous to (7):

$$
s_{F C G}^{D}=y_{U}\left(n_{G O}+n_{G U}\right)+n_{P O} y_{O} .
$$

The unification of GKV and PKV to a so-called citizens insurance results in a profit function

$$
\pi_{F C}^{B}=\left(n_{G O}+n_{G U}+n_{P O}\right) \cdot\left(y_{U} \cdot s_{F C}^{B}+\gamma^{B}\right)-\frac{1}{2} \cdot\left[s_{F C}^{B}\right]^{2}
$$

and drug quality:

$$
s_{F C}^{B}=y_{U} \cdot\left(n_{G O}+n_{G U}+n_{P O}\right)<s_{F C G}^{D} .
$$


By the solidarity-based funding of GKV (13) is given and by (13) we obtain: $s_{F C}^{B}<s_{F C G}^{D}$. Introducing a citizens' insurance will negatively affect the quality of new drugs, i.e. the PKV's existence is strengthened by the good quality of care.

Given a GKV-country's population structure the resulting the subsidy is analogous to (9):

$$
\gamma_{G}^{D}=\frac{\left[y_{O}\left(n_{G O}+n_{P O}\right)\right]^{2}-\left[y_{U}\left(n_{G O}+n_{G U}\right)+y_{O} \cdot n_{P O}\right]^{2}}{2\left(n_{G O}+n_{G U}\right)}
$$

Introduction of a citizen insurance leads to the following subsidy:

$$
\gamma^{B}=\frac{\left[y_{O}\left(n_{G O}+n_{P O}\right)\right]^{2}-\left[y_{U}\left(n_{G O}+n_{G U}+n_{P O}\right)\right]^{2}}{2\left(n_{G O}+n_{G U}+n_{P O}\right)} .
$$

Thus,

$$
y_{O}>\frac{n_{G O}+n_{G U}+n_{P O}}{n_{G O}+n_{P O}} \cdot y_{U} \equiv y_{O}^{\overline{\min }}<y_{O}^{\overline{\min }},
$$

is the necessary income disparity. The citizen insurance's minimum income disparity is below the existing GKV minimum income disparity. That is to say, universal coverage without any subsidies is reached at a further step of income convergence in the existing system of GKV and PKV, because of the MNC's ability to discriminate prices. Furthermore, by (13) we obtain:

$$
\gamma^{B} \geq \gamma_{G}^{D}
$$

Unifying GKV and PKV to citizens' insurance leads to higher subsidies being necessary to persuade full coverage. The full sums of subsidies are $n_{G U} \gamma_{G}^{D}$ in the bipartite system and $n_{G U} \gamma^{B}$ in the case of a citizens' insurance. Therefore the introduction of a citizens' insurance leads to a higher degree of redistribution. On the one hand the citizen insurance's drug price is negatively affected by the decreasing drug quality; on the other hand the higher degree of redistribution affects the citizens insurance's drug price positively.

In general, it is assumed that a convergence of GKV's und PKV's compensation - a vital requirement for the introduction of a citizen insurance - leads to higher GKV compensations. Lower PKV's compensations put the care provider's economic existence at risk. In our model the existing prices are:

$$
P_{P}=y_{O} \cdot s_{F C G}^{D}=y_{O} y_{U}\left(n_{G O}+n_{G U}\right)+y_{O}^{2} n_{P O}
$$

respectively

$$
P_{G}=y_{U} \cdot s_{F C G}^{D}+\gamma_{G}^{D} \text {. }
$$

By (9) and (13) it is straight forward that $P_{P}>P_{G}$ and the PKV member's drug prices are higher than the GKV member's drug prices. The PKV's importance for the drug quality is now obvious: together with their financial power, their higher valuation for quality affects the drug quality positively. The citizen insurance's drug price is:

$$
P_{B}=y_{U} \cdot s_{F C}^{B}+\gamma^{B} \text {. }
$$

By the citizen insurance's minimum income disparity we obtain that the PKV member's drug price exceeds the drug price within a citizen insurance $\left(P_{P}>P_{B}\right)$. Members of the PKV would on the one hand face a decreasing drug quality; on the other hand they have to pay less for new, innovative drugs. From equation (13), we obtain $P_{G}<P_{B}$, i.e. if a citizens' insurance is introduced, former GKV member's face increasing drug prices as well as decreasing drug quality. From this point of view the introduction of a citizens' insurance negatively affects prior members of GKV. The bipartite German health system advantages especially members of the GKV through higher drug quality and lower drug prices. Because of the pharmaceutical corporations' possibility to 
discriminate prices between GKV and PKV, the latter supports the first's goals of qualitative high coverage and efficiency. At least the analysis of the regarding welfare functions reveals that welfare decreases with the introduction of a citizens' insurance.

With the introduction of AMNOG, price negotiations between Federal Association of Statutory Health Insurance Funds and manufacturers of innovative drugs are introduced involving at least the PKV. Drug price convergence between PKV and GKV is a consequence. Further discount agreements between individual funds and manufacturers are possible. Considering the results of our analysis these individual discount agreements are vital for reaching the GKV's goals of qualitative high coverage and the efficiency principle. The possible individual discount agreements had not been sufficient from the PKV's point of view. From the GKV member's point of view, the importance of individual discount agreements should be enhanced, if the PKV's disability to negotiate individual discounts continues.

\section{Conclusion}

Access to health care, the efficiency principle and treatments of high quality are goals of the German Statutory Health Insurance. The existing German health care system consists of the statutory health insurance and private health insurance; these parts converge more and more. The legal framework puts pressure on this convergence to citizens' insurance. With our game theoretic approach we have shown that especially members of the statutory health insurance suffer from the introduction of citizens insurance via decreasing drug quality and increasing prices. Those insured by private health care also suffer from decreasing drug quality but benefit from decreasing drug prices.

The introduction of AMNOG results in price negotiations for innovative drugs between manufacturers and the Federal Association of Health Insurance Funds involving the PKV. Afterwards, individual discount agreements between manufacturers and funds are possible. According to this procedure, price discrimination is less likely and the PKV member's drug prices should decline. Based on the findings with citizens insurance, we assume a decreasing drug quality resulting from AMNOG. The innovative drug quality's decrease is substantially dependent on the possibility of price discrimination resulting from the individual discount agreements. The statutory health insurance would profit from the private health insurance's inability to negotiate sufficient discounts. This disability would also induce a lower reduction of drug quality.

\section{References}

Acemoglu, D., \& Linn, J. (2004). Market Size In Innovation: Theory And Evidence From The Pharmaceutical Industry. The Quarterly Journal of Economics, 119, 1049-1090. http://dx.doi.org/10.1162/0033553041502144

Acharyya, R., \& García-Alonso M. D. C. (2009). Health systems, inequality and incentives to innovate. Canterbury: Univ. of Kent, Dep. of Economics, 2009, KDPE 0902.

Acharyya, R., \& García-Alonso, M. D. C. (2008). Parallel Imports, Innovations and National Welfare: The Role of the Size of Income Classes and National Markets for Health Care. The Singapore Economic Review, 53(1), 57-79. http://dx.doi.org/10.1142/S0217590808002847

Acharyya, R. (1998). Monopoly and product quality. Separating or pooling menu? Economic Letters, 61, 187-194. http://dx.doi.org/10.1016/S0165-1765(98)00173-6

Acharyya, R. (2005). Quality discrimination among income constrained consumers. Economic Letters, 86, 245-251. http://dx.doi.org/10.1016/j.econlet.2004.07.015

Bardey, D., Bommier, A., \& Jullien, B. (2010). Retail price regulation and innovation: Reference pricing in the pharmaceutical industry. Journal of Health Economics, 29, 303-3016. http://dx.doi.org/10.1016/j.jhealeco.2009.11.015

Brekke, K. R., Königbauer, I., \& Straume, O. R. (2007). Reference pricing of pharmaceuticals. Journal of Health Economics, 26, 613-643. http://dx.doi.org/10.1016/j.jhealeco.2006.11.003

Council of the European Union. (2006). Press Release 2733rd Council Meeting Employment, Social Policy, Health and Consumer Affairs, Luxembourg, 1-2 June 2006.

Deutscher Bundestag. (2010). Bundestag-Drucksache 17/3116. (2010). Entwurf eines Gesetzes zur Neuordnung des Arzneimittelmarktes in der gesetzlichen Krankenversicherung (Arzneimittelmarktneuordnungsgesetz AMNOG).

Di Masi, J. A., \& Paquette, C. (2004). The Economics of Follow-on Drug Research and Development. 
Pharmacoeconomics, 22(2), 1-14. http://dx.doi.org/10.1016/S0167-6296(02)00126-1

DiMasi, J. A., Hansen, R. W., \& Grabowski, H. G. (2003). The price of innovation: new estimates of drug development costs. Journal of Health Economics, 22, 151-185.

DiMasi, J. A., Hansen, R. W., Grabowski, H. G., \& Lasagna, L. (1991). Cost of innovation in the pharmaceutical indsutry. Journal of Health Economics, 10, 107-142. http://dx.doi.org/10.1016/0167-6296(91)90001-4

European Parliament. (2011). Reducing health inequalities in the EU INI/20102089.

Grossman, M. (1972). On the Concept of Health Capital and the Demand for Health. Journal of Political Economy, 80(2), 223-255. http://www.jstor.org/stable/1830580

Heuer, A., Mejer, M., \& Neuhaus, J. (2007). The national regulation of pharmaceutical markets and the timing of new drug launches in Europe. Kiel advanced working papers, No. 437.

Institut für Qualität und Wirtschaftlichkeit im Gesundheitswesen (IQWiG). (2011). General Methods, Version 4.0, 23.09.2011.

Kifmann, M., \& Neelsen, S. (2010). Germany's Struggle With Prices For Patent-Protected Drugs. CESifo DICE Report 3/2010, 43-52.

Kim, J.-H., \& Kim, J.-C. (1996). Quality choice of multiproduct monopolist and spill-over effect. Economic Letters, 52, 345-352. http://dx.doi.org/10.1016/S0165-1765(96)00872-5

Mussa, M., \& Rosen, S. (1978). Monopoly and Product Quality. Journal of Economic Theory, 18, 301-317. http://dx.doi.org/10.1016/0022-0531(78)90085-6

Sloan, F.A., \& Hsieh, C. H. (2008). The Effects of Incentives on Pharmaceutical Innovation. In: Sloan, F.A., Hirschel, K. (Eds.), Incentives and Choices in Health Care. The MIT Press, Cambridge, Massachusetts.

\section{Note}

Note 1. It is stated in (11a) that $\gamma_{i}^{\min }$ has to be slightly above zero in the case of $\gamma_{i}^{D}$. 